\title{
Техногенные идеалы и гуманитарные ценности в цифровом обществе
}

\author{
Л.А. Королева \\ Российский государственный педагогический университет им. А.И. Герцена \\ kl ada69@ma i I.r u
}

\section{Аннотация}

В статье исследуется природа возникновения техногенных идеалов и делается попытка определить сущность и причины проблемы снижения гуманитарных ценностей в условиях информатизации.

По мнению автора, идея конвергенции техногенных идеалов и гуманитарных ценностей находит воплощение в Digital Humanities. Автор предлагает рассматривать Digital Humanities как перспективу развития гуманитарного знания и повышения его статуса с помощью цифровых технологий. В статье доказывается, что конфликт ценностей обусловлен трансформацией всей социальной реальности, а не развитием технологий и широким их распространением в сфере материального производства, в науке и культуре.

Анализ основан на рассмотрении изменений философии познания и менталитета в обществе. В рассмотрении проблемы гуманитарных ценностей особая роль в смещении ценностных ориентиров в общественном сознании отводится воздействию массовой культуры и медиа технологий, коммерциализации образования и культуры. Автор доказывает, что надо ставить вопрос не о приоритете техногенных идеалов или гуманитарных ценностей, а о более гармоничной парадигме познания, в которой технологическая составляющая социума неотделима от его духовной составляющей.

Ключевые слова: техногенные идеалы, гуманитарные ценности, философия познания, Digital Humanities, медиакультура

Библиографическая ссылка: Королева Л.А. Техногенные идеалы и гуманитарные ценности в цифровом обществе // Информационное общество: образование, наука, культура и технологии будущего. Выпуск 3 (Труды XXII Международной объединенной научной конференции «Интернет и современное общество», IMS2019, Санкт-Петербург, 19 - 22 июня 2019 г. Сборник научных трудов). - СПб: Университет ИТМО, 2019. С. 128 - 138. DOI: 10.17586/2587-8557-2019-3-128-138

\section{1. Введение}

Научное гуманитарное знание, культура и образование представляют собой институты, где происходит создание гуманитарных ценностей: сосредоточение функций познания, формирования национальной идентичности, сохранения исторической памяти народа и художественного наследия, а также нравственных норм. Усиление роли технологий в информационном обществе, изменения в медиакультуре и в массовом сознании, безусловно, оказало влияние на формы философию познания и культуру.

Гуманитарные ценности традиционно создавались и сохранялись культурой. С распространением информационных технологий произошла ломка привычных форм институционализации создания и обмена создаваемых в культурном пространстве знаний и продуктов творческой деятельности. Автор считает, что причины опасности снижения значимости гуманитарных ценностей следует искать в характере современной социальной 
реальности, и проблему следует рассматривать через декомпозицию на основе принципа системности общественной жизни, который нашел отражение в трудах крупных мыслителей последних двух столетий: О. Конта, Г. Спенсера, Э. Дюркгейма, М. Вебера, П. А. Сорокина, Т. Парсонса, Ю. Хабермаса и др. Применительно к теме данного исследования данный принцип означает, что материальная, духовная, социальная сферы общественной жизни при таком подходе находятся под воздействием взаимного влияния.

Феноменология, как направление, ориентированное на выявление основ познания человеческого существования и культуры, наряду с когнитивной и индивидуальной выделяет так называемую социальную реальность. Социальная реальность в целом объединяет в себе тенденции, социально принятые в обществе. По нашему мнению, социальная реальность складывается под воздействием различных мотивов, из которых, во-первых, для исследования интересны изменения в философии познания и культуре мышления, во-вторых, - способы распространения знаний, в-третьих, - техногенные идеалы на фоне развития цифровых технологий.

Одним из результатов трансформации социальной реальности становится риск снижения значения гуманитарного знания и снижение оценки духовных ценностей в сравнении с объективным ростом значения и идеализации технологий.

\section{2. Исследование новой ментальности: риски «цифровой» идеализации и механизм}

\section{1. Медиальность и «социальное действие» в институализации ценностей в обществе}

Если обратиться к «модели системы действия» философии американского теоретика социологии Парсонса [1], то можно определить подходы к пониманию того, как связны духовные и общественно-экономические основания социальной реальности и какое значение имеют ценности в обществе. В этом контексте уместным представляется использование понятие институализации ценностей как о механизме их формировании в социуме. «Модель системы действия» Парсонса была разработана им в результате выводов о том, что не экономические отношения связывают общество, а общность ценностей и взаимное соблюдение людьми правил социального поведения. В терминах этой теории действия и мышление индивидуумов регулируются системой действия, и невозможно отделить социальные системы от культурно-ценностных стандартов.

Идеалы и гуманность общества в модели Т. Парсонса находятся на высшем уровне. Образы знания, верования действий, ценностей содержатся в культуре, которая принадлежит высшему уровню. По выражению Т. Парсонса более высокий уровень потребляет «энергию» нижнего уровня. Система действия удовлетворяет большую часть потребностей то части субъектов, которая активно поддерживает ее своим в ней участием. Отсюда - стремление системы иметь единый язык и правила коммуникации и возможность контроля поведения своих элементов. Как мы видим, в действительности это стремление находит выход в массовой культуре через использование технологий медиа, что означает обязательное присутствие цифровых технологий.

По нашему мнению, культура в настоящее время возможно в большей степени сопричастна с процессами системы, чем ранее, до эпохи развития медиатехнологий. В философии изменения базовых ключевых оснований традиционно обозначаются как методологические повороты. В 21 веке последним, обобщающим поворотом был признан медиальный поворот (Medial turn). Под медиа стали понимать совокупность технологических средств и приёмов коммуникаций, служащих для передачи потребителю информационного сообщения виде текста, музыки, изображения. Но узкое понимание не охватывало всех сторон феномена, и более широкое прочтение стало предполагать рассмотрение в качестве медиального все в процессе и вокруг процесса от возникновения информации и смыслов до их интерпретации в восприятии человека и общества. 
Это означало, что медиальность присуща языку, образу, пространству, риторике, не только любому способу, но и условию восприятия. Появление философского термина «медиальный поворот» отвечал потребности выразить идею о том, что действительность опосредована через цепочку «мышление - язык - знак - медиа» [2]. Наполнение цифровыми образами и отказ от объективности реальности дали возможность выделить новое понятие «медиареальность». Медиальный поворот для механизма познания выразился в том, что индивидуальное восприятие действительности стало происходить в реальности медиатехнологий и формирующейся медиакультуры и стало зависеть от формата получаемой информации. Медиареальность затрагивает социальные, нравственные, психологические, интеллектуальные и даже художественные аспекты.

В «теории социального действия» Т. Парсонса социальное действие нуждается в рамках, которые и задаются системой ценностных и нормативных символов. Именно эти задачи, задачи создания такой системы, единого пространства общих социальных ценностей, по нашему мнению, и решает медиакультура.

Медиакультура одновременно может служить закреплению базовых ценностей, но также и одновременно противоречить ее базовым ценностям. С точки зрения рисков снижения роли гуманитарных ценностей можно определить две конфликтные зоны. Отношения гуманитарных ценностей и техногенных идеалов цифровой цивилизации составляют первую зону, а во второй зоне - в конфликт с гуманитарными ценностями вступают некоторые ценности массмедиа. Далее проводится попытка определить, какие изменения в сознании человека происходят в условиях информатизации общества, и чем они вызваны, а также в чем проявляется противоречие обозначенных в статье ценностей.

\section{2. Особенности новых принципов познания и формирования идеалов цифровой культуры}

В вопросе противопоставления ценностей необходимым является определение особенностей нового менталитета в цифровом обществе. Преобладающие сейчас ориентиры на технологии и инновационный путь развития закономерно ведут к созданию техногенных идеалов. В информационном обществе роль цифровых технологий столь высока, что это неминуемо ведет к возникновению техногенных идеалов. Любые идеалы опираются на философию познания, и, в конечном счете, проявляются как результаты сложившегося менталитета. В чем же особенности нового «цифрового» менталитета современного человека, и с какими особенностями «цифрового» мышления связаны техногенные идеалы?

Цифровые технологии позволяют реализовать и развивать идею акторности, одну из новой философии сознания. Человеку свойственно наделять духовными характеристиками движимые и недвижимые предметы и явления неодушевленной природы и технического производства, и это опять же связано с особенностями современного сознания. Наделение материальных объектов агентностью стало одним из элементов акторно-сетевой методологии, которая получила развитие в исследованиях Латура по теории социологии. В цифровой культуре сами технологии, и в том числе Интернет, становятся акторами, и их действия перестают подчиняться логике создателей и начинают подчиняться своей собственной логике [3]. В искусстве вообще, и, в частности в таком его направлении, как медиа-искусство, цифровые технологии позволяют бессознательные объекты или даже машины включать в действие в качестве акторов. Это безусловно свидетельство идеализации мира технологий.

Другими основаниями меняющегося менталитета является идея самостоятельной ценности чувств, настроения, мыслей как самостоятельных предметов познания. Это наиболее ярко проявилось в области искусства. При этом неоднозначность прочтения может становиться не только следствием такого подхода, но и даже самоцелью художника. С этой особенностью связаны предметные мыслительные процессы, то есть возникающие по поводу освоения и рефлексии предметного мира. Концепция иллюзии 
предмета стала основой более широкого осмысления пространства и времени. [4]. И здесь благодатной почвой стали технические возможности выражения подхода. Именно цифровая форма представления образа и хранения информации помогла отказаться от понимания произведения как материального объекта, означающего еще одну ступень, на которой соединяются гуманитарная и технологическая составляющие нового менталитета.

Выражение техногенных идеалов можно видеть также и в том, что использование информационных технологий не просто стало неотъемлемым атрибутом нашей жизни, но без них у человека не может быть ощущения полноты и ценности существования [5].

Техногенные идеалы можно увидеть в том, что путь к благосостоянию индивидуума в настоящее время лежит через специальные профильные знания и умения, связанные с информационными технологиями. Образ современного специалиста ассоциируется с владением навыками работы в программах, без которых невозможны рабочие процессы практически во всех сферах на рынке труда. Знание становятся тождественным понятию «информация» и на первый план выступает умение находить информацию и сохранять ее. Поэтому начало наблюдаться проявление когнитивной пассивности большой части учащихся и снижение аналитических навыков. Несмотря на растущее осознание проблемы, этому вопросу недостаточно уделяется внимания на этапах школьного и университетского образования.

Другой критической точкой становится то, что технологии дают иллюзию избавления от сложных процессов и трудоемкости, но при этом возникает опасность «освобождения» от умственной креативной работы. При попытке передачи всех функций технологическим устройствам утрачивают свое значение навыки когнитивной функции человеческого интеллекта, а человек становится зависим от качества работы технологических устройств. В повседневной жизни и на работе человек тратит много усилий и времени на диалог с электронными устройствами, постепенно полагаясь на их память, измерительные действия и другие технические возможности, подстраивая интеллект под задачи, решаемые цифровыми методами. В то же время человек остается в состоянии информационной перегруженности и стресса, вызываемого скоростью сменяющихся задач, которые необходимо решать очень быстро. Все это, в конечном счете, ведет к ослаблению способности качественно решать нестандартные задачи, требующие необходимых лагов между задачей и поиском ее решения. Для решения некоторых задач необходимы навыки креативного мышления и накопление чувственного и других видов опыта, которые всегда были присущи гуманитарным переживаниям и гуманитарной мыслительной деятельности.

Познание многомерное понятие, предполагающие различные практики и различные ценности. Это подтверждается тем, какие формы принимает научные исследования, самим научным опытом. Практика проведения научных исследований обогатилась междисциплинарностью, цифровыми методами, переосмыслением содержания, целей, методологии познания. Понимание научного познания как сети элементов, соединенных набором разнообразных практик, позволяет увидеть закономерность технологических новаций в методах и направлениях гуманитарных наук и культуры. Гуманитарные науки не должны противопоставляться естественным наукам, хотя бы потому, что в производстве гуманитарного знания также используются цифровые технологии. Благодаря концептуальным сдвигам в философии познания, а также благодаря возможностям применения цифровых технологий происходит синтез общественных наук и технологий. И в рамках такого подхода появляется возможность говорить не столько о приоритете техногенных идеалов или гуманитарных ценностей, сколько о балансе гармонии различных ценностей, которые создаются и используются в процессе выработки модели познания и формирования знания в обществе.

Техногенные (цифровые) идеалы можно видеть том, что в восприятии человека образы, созданные с помощью цифровых технологий, становятся равноценными реальным объектам. Интересно, что это происходит одновременно с процессом поиска замены настоящих материалов и подлинных артефактов имитациями, искусственными 
материалами, репродуцированием. Такой процесс заменителей в мире материального производства обусловлен стремлением общества производить все больше, удовлетворять все большее количество потребностей, снизить издержки, включая ресурс как время.

Этической проблемой является конкуренция двух видов действительности: виртуальной и реальной. Вектор ценности несколько сместился в более привлекательной для новых поколений вторичной реальности, реальности, преобразуемой человеком с помощью технологий. На наш взгляд, здесь также проявило себя влияние сдвигов постмодернисткого мышления. В философии познания, а затем в литературе и других видах искусств, также можно наблюдать смещение объектности познания. В этом смещении иллюзии как переживание человеком своей связи с миром, вторичная реальность, обретает самостоятельность и становится объектом познания и творчества, стали целью самостоятельного изучения, то есть стали предметом познания. Кроме своих неотделимых естественно-материальных характеристик реальный объект стал интересен «потенциальной бесконечностью того, чем он может стать в контексте человеческой деятельности» [6]. При этом важно заметить, что работа с образами, модификациями явлений и объектов реальной действительности получила развитие благодаря технологиям, и более того, в случае компьютерного моделирования стала возможной только в пространстве цифровых технологий. Благодаря технологиям, позволяющим сверхпродуцирование «имиджей» гуманитарные науки могут анализировать обилие визуальных образов.

И, поскольку, информационные технологии обеспечили возможность оперировать с виртуальными объектами, можно говорить о другом типе или даже уровне познания. С появлением новых способов обработки информации и методов анализа познание смогло объединить прежде автономные области. Это можно видеть в том, как например, искусство заимствует характеристики научного поиска и даже синтезируется с наукой, используя технологии и знания, выработанные в области научного знания. Причем это проявляется до такой степени, что в некоторых случаях, когда речь идет о новых видах искусства или отдельных творческих экспериментах с использованием цифровых технологий, стирается грань между искусством и наукой.

Трудно определить, что первично было для современной методологии познания: сдвиги в философии познания и связанные с ними новые идеалы познания или же это новые технологии, определяющие характер познания. То и другое явилось результатом развития знания и интеллектуальной деятельности и вписалось в социальную реальность как неотделимые элементы.

Предпосылками принципиально новой культуры мышления и новых философских основ познания стали замена понятийного мышления образным мышлением, нелинейная психология восприятия и концепция иллюзии. А медиатехнологии и цифровые технологии в искусстве как способы создания и распространения контента стали не только проводником нового мышления, но и мастерской, где культура мышления продолжает находить новые ракурсы. Таким образом, логический круг замыкается.

В качестве философских основ развития культуры познания можно выделить идеи Бергсона. Первая идея состоит в том, что необходимо рассматривать мир как динамичный, творческий, непрестанно развивающийся. Вторая идея воплотилась в понимании невозможности рациональной составляющей интеллекта воспроизвести реальность, и в предложении перенести этой функцию на интуицию [7].

Трудно переоценить значение цифровых медиатехнологий в области сохранения и реставрации гуманитарных ценностей. Цифровые технологии позволяют актуализировать культурное наследие традиционной духовной, художественной и материальной культуры. Дублирование духовных и художественных ценностей культуры в виртуальной реальности обеспечивает более широкий доступ к информации исторической культурной и художественной тематики. 
Другой непротиворечащей гуманитарным идеалам сферой цифровых технологий является создание интерактивного взаимодействия инициаторов-художников медиапроектов и участников-зрителей. Фестивали выставки и другие акции цифрового медиаискусства несут не только пример коммуникаций, но рождение новых идей и форм познания мира и самоидентификации. Несмотря на коммуникативный характер, здесь нет стандартизации, клише и массовости как в средствах массовой информации. Здесь в меньшей степени присутствует институциональная зависимость, коммерциализация (зачастую эти виды медиаискусства носят некоммерческий характер), выражен экспериментальный индивидуально-творческий характер деятельности. В новых видах цифрового медиаискусства мы не найдем рекламы, навязанных моделей социального поведения и создания архитипов. В настоящее время сохраняется незаказной характер мероприятий цифрового медиаарта в формах дигитал-перфоманса, видеоарта, дигиталданса и др.

Поэтому не следует отождествлять медиакультуру, медиатехнологии, цифровые медиатехнологии, цифровое искусство. На наш взгляд, не меньшую, а скорее большую опасность, чем идеализация технологического духа социальной реальности, представляет опасность духа растворения гуманитарных ценностей в коммерческих или политичных продуктах медиакультуры.

Приходится признать, что далеко не всем обществом оценивается опыт предшествующих поколений как необходимая основа мировоззрения и самоидентификации, а для молодого поколения характерно не только отсутствие интереса «устаревшим» культурным ценностям прошлого, но и игнорирование духовной составляющей как малозначимой для реальности их существования.

Владеть цифровыми коммуникативными технологиями, быть вовлеченным в социальные сети, «быть в тренде», иметь работу, дающую возможность быть субъектом общества потребления, - все это заменяет молодому человеку другие ценности традиционной культуры, где служить возвышенным идеалам являлось высшей целью человеческого существования. Ценности масштаба мировой культуры в глазах потребителей массовых зрелищ утратили свою ценность, так как время и деньги потребителей теперь представляют собой объект интереса коммерческих структур и политических институтов. Потребителю предложены в качестве заменителей широкодоступные и более простые, «легко усвояемые» продукты массовой культуры в виде программ новостей, поп-музыки, сериалов, ток-шоу, глянцевых журналов, детективной литературы и книг в жанре фэнтези. Со стороны цифровых технологий индустрией массовой культуры ему предложены компьютерные игры и социальные сети. Нельзя не признать, что доступность продуктов массовой культуры выше, чем уникальных артефактов культурного наследия ввиду количества производства, а также его выгодности, так как производство обеспечено спросом, подготовленным социальными паттернами и медиатехнологиями рыночного продвижения.

\section{3. Конвергенция гуманитарных ценностей и техногенных идеалов}

Представленный выше анализ строился на противопоставлении техногенных идеалов и гуманитарных ценностей, как разнополярных явлений. Этот ракурс позволил вплотную подойти к проблеме риска снижения значения гуманитарных ценностей и обосновать актуальность обсуждения данной проблемы. Несмотря на существование проблемы, в информационном обществе происходит конвергенция техногенных идеалов и гуманитарных ценностей, которую автор предлагает рассматривать как перспективу сохранения и повышения статуса гуманитарного знания в цифровом пространстве с помощью цифровых технологий, и одновременно как расширения поля цифровых технологий. Интеграция техногенных идеалов и гуманитарных ценностей воплотилась 
активно развивающемся с 70-80-е гг. направлении, получившем название Digital Humanities.

По мере накопления опыта в этой области была осознана необходимость в выделении отдельной науки, в рамках которой происходили бы исследования процессов синтеза информационных знаний, науки и искусства. Однако становление такой дисциплины вызвало дискуссии о наполнении и сфере действия. Задачи, описанные в манифесте 2009 г. [8] оставили неясные представления о содержании Digital Humanities. В числе задач были названы научные инновации, дисциплинарные кросс-оплодотворения и демократизация знания. Сразу был обозначен широкий диапазон, но не было предложено строгой классификации. Поэтому и в настоящее время продолжаются споры о научном и дисциплинарном статусе DH. Нередко Digital Humanities отводится роль новой методологии.

Основополагающей особенностью Digital Humanities стала мультидисциплинарность, так как в этот класс наук было включено много различных направлений: цифровые (информационные науки), гуманитарные науки и социальные (история, антропология, искусство и архитектура, кино и медиаисследования, археология, география). Большое значение цифровые гуманитарные дисциплины имеют для расширения возможностей образовательного процесса.

DH поучили развитие в различных направлениях, в рамках которого можно выделить DH-проекты различного типа: Визуализация данных, Open data, Big data, Краудсорсинг.

Одним из примеров Open data может выступать TEI (Text encoding initiative) - проект, нацеленный на создание декодирующих методов для компьютерной обработки в гуманитарных и социальных науках. Направление Big data занимает одно из пяти главных направлений развития цифровой экономики Великобритании. Среди проектов краудсорсинга можно назвать проект Би-Би-Си «Your Paintings», проект Университетского Колледжа Лондона «Transcribe Bentham», проект «The Great War Archives» Оксфордского университета.

Новым словом в гуманитарных исследованиях и популяризации культурноисторических ценностей стали проекты, работающие по принципу цифровой исторической карты. Например, карта исландской саги позволяет пользователям изучать не только текст норвежских саг, но их географию. Ресурс посредством ссылок знакомит нас с изображением и описанием мест, упоминаемых в литературе, с археологическими раскопками и другой справочной информацией. Другим известным проектом стал проект The Cambridge World Shakespear Encyclopedia («Кембриджская всемирная шекспировская энциклопедия»).

Если рассмотренные выше проекты представляют собой готовый продукт, то другим принципиально иным типом открытого проекта в области цифровой гуманитаристики являются ресурсы, предполагающие участие пользователей в общих исследованиях. Крупный международный проект Project Bamboo ориентирован на создание новых программ для гуманитарных исследований, как например Woodchipper, уже созданный в рамках проекта инструмент текстологического анализа. Особенностью проекта является взаимодействие исследователей через социальные сети. Другим примером служит французский проект Sidore, представляющий собой библиотеку данных по истории, социологии, философии, литературоведению, лингвистике, политологии и др. дисциплинам с расширенными возможностями поиска и скачивания в формате pdf. Группы исследователей и университеты могут пополнять каталог, размещая собственные материалы.

Немецкий проект TextGrid, в результате своего развития постепенно сформировавшийся как виртуальная среда (VRE) представляет собой сотрудничество историков, искусствоведов, музыковедов, и специалистов в области других гуманитарных дисциплин. К настоящему времени сервис имеет не только текстовые, но и мультимедийные материалы, к проекту уже подключились немецкие университеты и 
библиотеки. Так партнерами проекта стали Берлин-Бранденбургская, Университет прикладных наук Вормса, Геттингенский университет, Геттингенская государственная и университетская библиотека и др.

Появление цифровых гуманитарных наук потребовало разработки своей теории и научного обоснования. В области теоретизации DH хочется выделить Патрика Свенссона. Патрик Свенссон стал известен благодаря его работе в HUMlab в университете Умео. Такие гуманитарные лаборатории или, как их еще называют, центры DH специализируются на различных видах исследований. В их число входят статистические исследования на основе методов компьютерной лингвистики, исследования текстового наследия с помощью программы TEI, и анализ визуального образа, пространственные исследования в гуманитарных науках с использованием картографического программного обеспечения (Google Earth или Google Maps).

Сквозной темой работ П.Свенссона, которые представлены серией четырех очерков, опубликованных в Digital Humanities Quarterly с 2009 по 2012 год, стал переход от гуманитарных вычислений цифровым гуманитарным наукам как самостоятельной дисциплине, а также способам взаимодействия технологий и гуманитарных наук. Он поднимает проблему создания необходимых условий для развития нового типа наук киберинфраструктуры $[9,10]$.

Из исследований по DH можно выделить кроме работ П.Свенссона монографию коллектива [11] Томского университета, в которой представлен анализ того, как происходит распространение центров DH в мире. Данная работа представляет собой на сегодняшний день аналитический отчет о распространении DH в мировом практике. Следует отметить широту поставленных предметных вопросов изучения и разнообразия методов, включающих контент-анализ, элементы ГИС-технологий, визуализацию информации о публикациях и центрах DH. Томские исследователи выделили более 100 направлений деятельности $\mathrm{DH}$, что свидетельствует о растущей конвергенции между технологическими знаниями и гуманитарными практиками и науками. В исследовании выявлено, что Digital Humanities как дисциплина в образовании представлена во всех ведущих университетах Великобритании, США, Канады, Австралии, Голландии, др. странах Европы. С 2000-г. наблюдается заметный рост числа центров DH и количества публикаций в области цифровой гуманитаристики по всему миру.

\section{4. Заключение}

Подводя итоги, следует заметить, что все формы деятельности человека (наука, экономика, культура и медиакультура), и генерируемые этими сферами ценности имеют общее время и общий социальный фон. Анализ позволил сделать вывод, что причина того, что техногенные идеалы вступают в противоречие с гуманитарными ценностями, следует отнести к проблеме социальной реальности. Философия познания, с одной стороны, является наукой, и она изучает то, что уже происходит в общественном сознании и отражается в различных сферах человеческой деятельности. С другой стороны, сама философия является областью воздействия на социальную реальность. Но именно в философии познания должна быть сформирована модель познания, дающая возможность убрать с повестки дня проблему конфликта гуманитарного и технологического в ценностной ориентации.

Информатизация наук о культуре и обществе породила новое бурно развивающееся направление, которое получило название eHumanities или Digital Humanities. Если сначала этот термин объединял только практику использования новых информационных технологий для задач сохранения, реконструкции, передачи и интегрирования знаний людей, то в дальнейшем стал целым классом цифровых гуманитарных наук и практик.

Проблему снижения статуса гуманитарных наук, по нашему мнению, следует связывать в первую очередь, не с информатизацией общества и проникновением 
технологий в нашу жизнь, a c отходом от гармоничной модели познания; коммерциализацией производства области культуры и гуманитарного знания; с попыткой замены ценностей культуры продуктами массовой культуры. Коммерциализация отразилась на качестве среднего и высшего образования, именно той области, где формируется когнитивный аппарат личности, закладывается отношение к знанию, культура мышления, где человек учится решать интеллектуальные и методологические задачи. Поэтому именно сфере образования отводится большая роль в решении проблемы гармоничного развитии технологического и гуманитарного знания, особенно в вопросах развития когнитивных методов и формирования когнитивных способностей.

Использование технологий может давать различные эффекты в общественной жизни, в науке, культуре и искусстве. Сохранение гуманитарных ценностей и создание их в новых формах уже невозможно представить без цифровых технологий. Более того, цифровые технологии в области музейных медиатехнологий могут даже рассматриваться объект инженерного и изобразительного искусства, если разработаны под определенную музейную задачу и интерактивные инсталляции воплощают технологические, эстетические и гуманитарные ценности.

Мы уже становимся свидетелями радикальных изменений в методологии гуманитарного знания, вызванных проникновением цифровых технологий в гуманитарные сферы. Поэтому вопрос следует ставить не о приоритетности техногенных идеалов или их отрицании, а о важности возвращения статуса гуманитарным ценностям через осознание неотделимости духовной составляющей социума от технологической и материальной, а также через такую парадигму познания, которая исключала бы актуальность проблемы конфликта ценностей в постиндустриальном обществе.

\section{Литература}

[1] Парсонс Т. О структуре социального действия: Пер. с англ. - М.: Академический проект, 2018. - 435 с.

[2] Антология медиафилософии / Редактор-составитель В. В. Савчук. - СПб: Издательство РХГА, 2013. - 339 с.

[3] Латур Б. Пересборка социального. Введение в акторно-сетевую теорию / пер.с англ. И. Полонской. М.: Изд-во ГУ ВШЭ, 2014. С. 158.

[4] Королёва Л.А. Цифровая эволюция искусства: социо-культурный анализ в контекстах философии и культуры постмодерна // Электронный мультимедийный журнал «Культура и технологии», 2018. Том 3, Вып. 1-2. С. 20-28. URL: http://cat.ifmo.ru/ru/2018/v3-i1/128.

[5] Никонова А.А. Гуманитарные ориентиры техногенной среды/ Электронный мультимедийный журнал «Культура и технологии», 2017. Том 2, Вып. 3 URL: http://cat.ifmo.ru/ru/2017/v2-i3/116.

[6] Гарифуллин Р.Р. Постмодернистская психология смысла. Введение в постмодернистскую (неклассическую) психологию. URL: http://www.psyfactor.org/lib/postmodern.htm.

[7] Бергсон А. Творческая эволюция. (L’Evolution creatrice) монография. - Пер. с фр. В. Флеровой; Вступ. ст. И. Блауберг. - М.: ТЕРРА-Книжный клуб; КАНОН-пресс-Ц, 2001. - 384 c. URL: http://www.litresp.ru/chitat/ru/\%D0\%91/bergson-a/tvorcheskayaevolyuciya.

[8] The digital humanities Manifesto 2. URL://http://www.humanitiesblast.com/manifesto/ Manifesto_V2.pdf.

[9] Svensson P. Humanities Computing as Digital Humanities // Digital Humanities Quarterly. 2009. Vol. 3, № 3. URL: http://umu.diva-portal.org/smash/record.jsf?language= en\&pid= $=$ diva2 $\% 3$ A360995\&dswid $=1675$. 
[10] Svensson P. The Landscape of Digital Humanities // Digital Humanities. 2010. Vol. 4, № 1. URL: http://umu.diva-portal.org/smash/record.jsf?language=en\&pid=diva2\%3A360994\&dswid= 1675.

[11] Digital Humanities: гуманитарные науки в цифровую эпоху /под ред. Г.В. Можаевой. Томск: Изд-во Том. ун-та, $2016-120$ с.

\title{
Technogenic Ideals and Humanitarian Values in a Digital Society
}

\author{
L. Koroleva
}

\section{Herzen State Pedagogical University of Russia}

The article examines the nature of the emergence of technogenic ideals and attempts to determine the nature and causes of the problem of reducing humanitarian values in the context of informatization. According to the author, the idea of convergence of technogenic ideals and humanitarian values is embodied in Digital Humanities. The author proposes to consider Digital Humanities as a prospect for the development of humanitarian knowledge and the enhancement of its status by digital technologies application. The article proves that the conflict of values is due to the transformation of the whole social reality, rather than the development of technologies and their wide dissemination in the sphere of material production, in science and culture. The analysis is based on consideration of changes in the philosophy of knowledge and the culture of thinking in society. In explaining the conflict of values, the influence of mass culture and media technologies, the commercialization of education and culture is given a special role in the shift of value orientations in the public consciousness. The author argues that it is necessary to raise the question not about the priority of technological ideals or humanitarian values, but about a more harmonious paradigm of knowledge, in which the technological component of society is inseparable from its spiritual component

Keywords: humanitarian values, technogenic ideals, philosophy of knowledge, Digital Humanities, media culture

Reference for citation: Koroleva L. Technogenic Ideals and Humanitarian Values in a Digital Society // Information Society: Education, Science, Culture and Technologies of the Future. Vol. 3 (Proceedings of the XXII International Joint Scientific Conference «Internet and Modern Society», IMS-2019, St. Petersburg, June 19-22, 2019). - St. Petersburg: ITMO University, 2019. P. 128 - 138. DOI: 10.17586/2587-8557-2019-3-128-138

\section{Reference}

[1] Parsons T. O strukture sotsial'nogo dejstviya: Per. s angl. - M.: Akademicheskij proekt, 2018. - $435 \mathrm{p}$.

[2] Antologiya mediafilosofii / Redaktor-sostavitel' V. V. Savchuk. — SPb: Izdatel'stvo RKHGA, 2013. - 339 p.

[3] Latur B. Peresborka sotsial'nogo. Vvedenie $\mathrm{v}$ aktorno-setevuyu teoriyu / per.s angl. I. Polonskoj. M.: Izd-vo GU VSHEH, 2014. P. 158.

[4] Korolyova L.A. TSifrovaya ehvolyutsiya iskusstva: sotsio-kul'turnyj analiz v kontekstakh filosofii i kul'tury postmoderna [EHlektronnyj tekst] // EHlektronnyj mul'timedijnyj zhurnal «Kul'tura i tekhnologii», 2018. Tom 3. Vol. 1-2. P. 20-28. URL: http://cat.ifmo.ru/ru/2018/v3-i1/128.

[5] Nikonova A.A. Gumanitarnye orientiry tekhnogennoj sredy/ EHlektronnyj mul'timedijnyj zhurnal «Kul'tura i tekhnologii», 2017. Tom 2, Vyp. 3 URL: http://cat.ifmo.ru/ru/2017/v2i3/116.Latur B. Peresborka sotsial'nogo. Vvedenie v aktorno-setevuyu teoriyu / per.s angl. I. 
Polonskoj. M.: Izd-vo GU VSHEH, 2014. S. 158 Latur B. Peresborka sotsial'nogo. Vvedenie v aktorno-setevuyu teoriyu / per.s angl. I. Polonskoj. M.: Izd-vo GU VSHEH, 2014. P. 158

[6] Garifullin R.P. Postmodernistskaya psikhologiya smysla. Vvedenie v postmodernistskuyu (neklassicheskuyu) psikhologiyu. URL: http://www.psyfactor.org/lib/postmodern.htm.

[7] Bergson Anri. Tvorcheskaya ehvolyutsiya. (L'Evolution creatrice) /monografiya. - Per. s fr. V. Flerovoj; Vstup. st. I. Blauberg. - M.: TERRA-Knizhnyj klub; KANON-press-TS, 2001. - $384 \mathrm{p}$.

[8] The digital humanities Manifesto 2. URL: //http://www.humanitiesblast.com/manifesto/ Manifesto V2.pdf.

[9] Svensson P. Humanities Computing as Digital Humanities // Digital Humanities Quarterly. 2009. Vol. 3, (3). URL: http://umu.diva-portal.org/smash/record.jsf?language=en\&pid $=$ diva2\%3A360995\&dswid $=1675$.

[10] Svensson P. The Landscape of Digital Humanities // Digital Humanities. 2010. Vol. 4, (1)/ URL: $\quad$ http://umu.diva-portal.org/smash/record.jsf?language=en\&pid=diva2\%3A360994 \&dswid=1675.

[11] Digital Humanities: gumanitarnye nauki v tsifrovuyu ehpokhu /pod red. G.V. Mozhaevoj. Tomsk: Izd-vo Tom. un-ta, $2016-120$ p. 